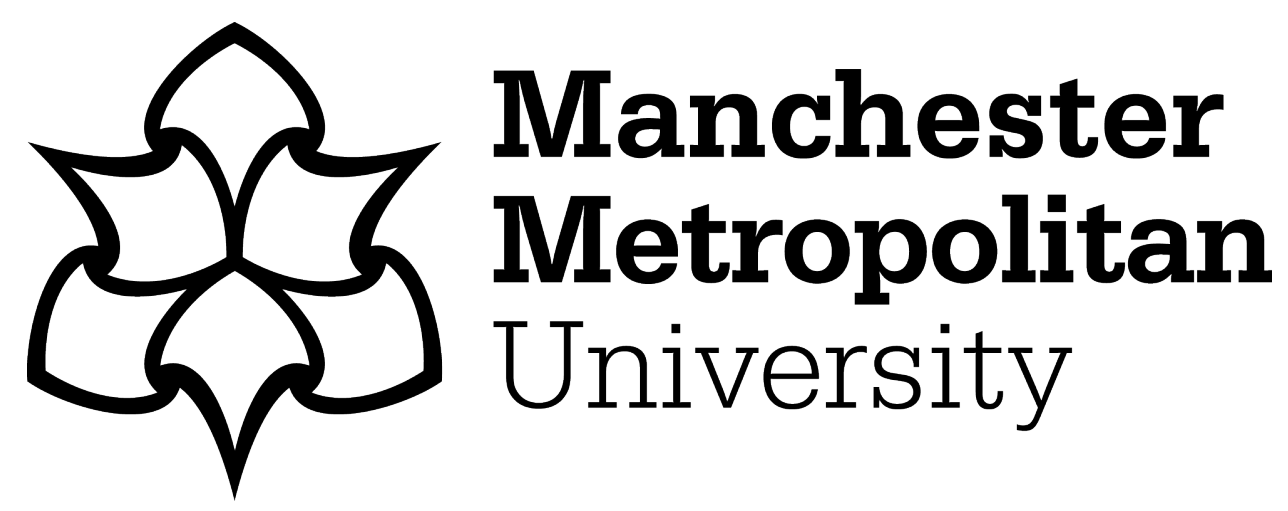

Davies, Emma L and Paltoglou, Aspasia (2019) Public self-consciousness, pre-loading and drinking harms among university students. Substance Use and Misuse, 54 (5). pp. 747-757. ISSN 1082-6084

Downloaded from: https://e-space.mmu.ac.uk/621614/

Version: Accepted Version

Publisher: Taylor \& Francis

DOI: https://doi.org/10.1080/10826084.2018.1536720

Please cite the published version 
Public self-consciousness, pre-loading and drinking harms among university students

\section{TITLE PAGE}

Authors: Emma L Davies ${ }^{1} \&$ Aspasia E Paltoglou ${ }^{2}$

1: Faculty of Health and Life Sciences, Oxford Brookes University, Oxford, OX3 0BO

2. Department of Psychology, Manchester Metropolitan University, Manchester, M15 6GX

Corresponding author: Emma L Davies edavies@brookes.ac.uk

Running head: Public self-consciousness, pre-loading and student drinking

Acknowledgements: We are grateful to the participants for giving up their time and to Sarah Hennelly for collecting the data.

Funding: This project was funded by the Oxford Brookes University Central Research Fund.

\section{Word count: 4989}

Statement of contribution: ED conceived the study, developed the measures, and analysed the open ended questions. AP searched for literature and drafted sections of the introduction and results. ED and AP jointly analysed the data and together wrote manuscript drafts and agreed on the final version of the manuscript.

Conflicts of interest: The authors declare no conflicts of interest.

\section{Biographies:}

Emma L Davies is a senior lecturer in psychology at Oxford Brookes University. Aspasia E Paltoglou is a lecturer in psychology at Manchester Metropolitan University. 


\title{
Public self-consciousness, pre-loading and drinking harms among university students
}

\begin{abstract}
Background: Social anxiety and self-consciousness are associated with alcohol-related problems in students. The practice of pre-loading is one avenue for exploration regarding this relationship. Individuals may pre-load to reduce social anxiety and feel more confident when socialising, which could lead to the increased harms experienced. The current study aimed to explore reasons for pre-loading, and whether public and private self-consciousness and social anxiety were related to pre-loading, increased drinking and harms.
\end{abstract}

Method: Prospective study with four-week follow up of 325 UK students aged 18-30 years old. Participants completed measures of private and public self-consciousness, social anxiety, alcohol consumption, alcohol-related harms and pre-loading.

Results: Financial motives and mood-related reasons, such as gaining confidence were reported as reasons for pre-loading. Pre-loading predicted hazardous alcohol consumption, but social anxiety, and public and private self-consciousness did not. However, pre-loading, public selfconsciousness and social anxiety predicted alcohol-related harms. Furthermore, public selfconsciousness mediated the relationship between pre-loading and harms in a positive direction and this appeared to be more relevant in high risk (AUDIT 8+) than low risk drinkers.

Conclusion: Students who scored higher in public self-consciousness appeared to be at greater risk of harms from pre-loading. Further research should examine this relationship further with particular attention to high risk drinkers, and explore which aspects of a night out are related to heightened self-consciousness. Interventions could incorporate measures to reduce public selfconsciousness, in order to reduce the negative impacts of pre-loading. 
Public self-consciousness, pre-loading and student drinking

\section{Public self-consciousness, pre-loading and drinking harms among university students}

\section{INTRODUCTION}

Excessive alcohol consumption is associated with a number of negative outcomes, with young people at high risk of harm (Babor et al., 2010; Rehm, Room, van den Brink, \& Jacobi, 2005). University students, in particular, tend to consume alcohol at harmful levels (Kypri, Cronin, \& Wright, 2005). A recent systematic review suggests two thirds of students in the United Kingdom (UK) and Ireland drink at hazardous levels (Davoren, Demant, Shiely, \& Perry, 2016). It is imperative, therefore, to explore factors that influence excessive consumption in this group. Social anxiety, public and private self-consciousness and pre-loading have been previously explored in relation to student drinking, but the relationship between these factors is less well understood.

\section{Social anxiety, public and private self-consciousness, and pre-loading}

Social anxiety and public and private self-consciousness appear to differentially influence student drinking. Studies suggest a negative relationship between social anxiety and consumption (Schry \& White, 2013) and a positive relationship between social anxiety and alcohol-related problems (Ham, Bacon, Carrigan, Zamboanga, \& Casner, 2016). Social anxiety is positively correlated with alcohol expectancies and indirectly associated with drinking behaviours through social expectations (Ham et al., 2016). Such results indicate that social anxiety could potentially lead to increased hazardous drinking (through positive expectations), or could protect against it, through negative expectations about drinking (Ham et al., 2016).

Self-consciousness is a specific trait related to self-awareness, and describes the tendency to direct one's attention either inwards (private self-consciousness) or outwards (public selfconsciousness) (Fenigstein, Scheier, \& Buss, 1975). Evidence is mixed as to whether public and private self-consciousness are associated with increased alcohol consumption. Some studies suggest that private self-consciousness is negatively related to drinking (LaBrie, Pedersen, 
Neighbors, \& Hummer, 2008b) whereas others have shown no relationship (Park, Sher, \& Krull, 2006). Higher levels of public self-consciousness, on the other hand, have been associated with increased drinking in female student sorority members (Park et al., 2006). Public selfconsciousness also moderated the relationship between drinking norms and alcohol consumption; the relationship between norms and drinking was greater for those who score lower in public self-consciousness (LaBrie, Hummer, \& Neighbors, 2008a). Other studies suggest that public self-consciousness might increase drinking in students who have a family member with alcohol problems (Crawford \& Novak, 2007).

It appears that public self-consciousness may have more of a relationship with the consequences of alcohol consumption. For example, public self-consciousness was associated with increased alcohol related consequences in American students (Crawford \& Novak, 2013; LaBrie, Pedersen, Neighbors, \& Hummer, 2008c). This might be because students who score highly in public self-consciousness feel the need to drink more in order to fit in with peers, leading to increased harm (Foster \& Neighbors, 2013).

There is a need to further explore why individuals who are high in social anxiety and public selfconsciousness experience more alcohol-related problems. The practice of pre-loading is one avenue for exploration. Individuals may pre-load to feel more confident when socialising and this could lead to the increased harms experienced. Private self-consciousness may also be related to drinking and pre-loading in a UK sample, and so all three parts of the scale were analysed in this paper.

\section{Pre-loading}

Pre-loading is a term used to describe the consumption of alcohol, usually at someone's home, prior to entering the night time economy (Foster \& Ferguson, 2014). It is also referred to as 'pre-gaming' or 'pre-drinking' in some US literature, but we use the term 'pre-loading' in line with other UK researchers. Although there are some UK studies, most have been conducted in other countries, including USA, Canada, Australia and New Zealand (Foster \& Ferguson, 2014). 
An international survey suggested that pre-loading is most prevalent in English-speaking countries, where drinking rates are also high (Labhart, Ferris, Winstock, \& Kuntsche, 2017).

Young people are often motivated to pre-load to save money by buying cheap alcohol from supermarkets (Wells, Graham, \& Purcell, 2009). Although price was the main reason young adults in New Zealand pre-load, their pre-loading practice was influenced by factors such as the expectation of enjoyment from being intoxicated, the desire to bond with their peers and expectations from their social groups (McCreanor et al., 2016).

Gender differences are often observed in pre-loading behaviours in the UK. Lower earning males may be motivated to pre-drink to reach the required levels of intoxication to participate fully in a night out, whereas females in all earnings categories are likely to see pre-drinking as an important part of the night out, and not just as a precursor (Østergaard \& Andrade, 2014). A qualitative study further revealed that pre-loading served to promote social connections for young women (Atkinson \& Sumnall, 2017). The home environment may also be perceived as a safer environment than bars and clubs to drink and get in the mood for the upcoming outing (Barton \& Kerryn, 2014). Young people may pre-load before going to a noisy bar to be able to socialize with their friends more effectively, and to reduce any feelings of awkwardness, anxiety and self-consciousness (Wells et al., 2009).

While social factors such as bonding with peers may positively impact individuals in the short term, pre-loading can lead to increased alcohol consumption during a night out. Individuals who engage in pre-loading consume more alcohol on average and are more frequently involved in violent incidents (Miller et al., 2016). A UK study found young adult (aged 18-35) pre-loaders were more likely drink in excess of 20 units of alcohol on a single night out than those who had not pre-loaded (Hughes, Anderson, Morleo, \& Bellis, 2008). In the same study, pre-loaders also experienced more negative consequences, such as being involved in fights.

Socially anxious and self-conscious individuals may therefore engage in more or less preloading than their peers. A previous study explored how one facet, social anxiety, was related to 
pre-loading in undergraduate students in Canada (Keough, Battista, O'Connor, Sherry, \& Stewart, 2016). Social anxiety positively predicted solitary pre-loading and this was subsequently related to greater alcohol-related harms. If there is a relationship between social anxiety, public and private self-consciousness and pre-loading in UK undergraduates then this could be a fruitful area for interventions.

\section{AIMS}

The current study therefore aimed to explore whether public and private self-consciousness and social anxiety, were related to pre-loading, increased drinking and harms in UK students. The specific aims of the study were as follows:

1) To understand reasons for pre-loading in UK students, and whether different reasons were associated with increased drinking and harms. It was expected that those who pre-load to reduce feelings of awkwardness, anxiety and self-consciousness, may drink more, experience more harms and score more highly on social anxiety and public self-consciousness.

2) To explore whether social anxiety, public and private self-consciousness and preloading differentially predict alcohol consumption and harms. It was that hypothesised pre-loading would positively predict consumption and harms and that social anxiety and public selfconsciousness would negatively predict consumption and positively predict harms.

3) To explore whether social anxiety and public and private self-consciousness mediate the relationship between pre-loading and alcohol consumption and harms. It was hypothesised that social anxiety and public self-consciousness would act as mediators such that in students who engaged in higher levels of pre-loading, higher scores on these scales would be associated with higher levels of consumption and harms.

No predictions were made for the effect of private self-consciousness, as previous research suggested it may be either negatively related or unrelated to drinking, but it was included in this study to explore its impact in a UK sample. 


\section{METHODS}

Participants and procedure

Student drinkers were invited to take part in an online study about drinking attitudes and behaviours. Study adverts were placed on social media and sent via email lists targeting students at one institution, and asking them to share the study with friends who might be willing to take part. Students consented online after reading the study information sheet. After completing the measures they were signposted to advice about alcohol, including details about where to get support if they were worried about their own or someone else's drinking. The study procedures were approved by Oxford Brookes University Research Ethics Committee (reference 150944)

Design and Measures

This was an online prospective study with four week follow up period. Email addresses were used to match Time one (T1) and Time two (T2) data, and these were deleted once data collection was completed.

\section{Alcohol}

Hazardous alcohol consumption was measured using the Alcohol Use Disorders Identification Test (AUDIT), which is a 10 item questionnaire, often used as a screening tool in healthcare settings (Babor, Higgins-Biddle, Saunders, \& Monteiro, 2001). Participants receive a score from 0-40 (0-7= low risk, 8-15= increasing risk 16-19= higher risk; $20+=$ possible dependence $)(10$ items; T1 $\alpha=.812 ; \mathrm{T} 2 \alpha=.830$ ).

The consequences of excessive drinking assessed within AUDIT include memory loss and guilt/ remorse but this tool does not assess more specific short-term impacts that are often experienced by students (Davies \& Joshi, 2018). Drinking-related harms experienced in the last four weeks were therefore measured using a scale used in a previous study with UK students 
(Davies, Martin, \& Foxcroft, 2016) and included: being sick; embarrassed; missing class; trouble with police; injury; taken to hospital; having a fight; taking an illegal drug; losing a personal item such as a phone; unprotected sex; regretted sex; not knowing where you are when you woke up; an embarrassing photo posted on social media (14 items; T1 $\alpha=.751$; T2 $\alpha=.725$ ). These items focus on short-term consequences of alcohol consumption, rather than problematic use and dependence as measured by items $4-10$ of the AUDIT scale.

Pre-loading was measured by asking 'How often in the last four weeks have you drank alcohol at home before going out on a night out? (1= never $-5=$ always). Participants were also presented with a text box and asked 'Why do you drink alcohol at home before going out?

\section{Self-consciousness}

Self-consciousness was measured using Fenigstein et al's (1975) 23-item self-consciousness scale. It has three subscales: public and private self-consciousness, and social anxiety. Private self-consciousness was measured using 10 items such as 'I'm always trying to figure myself out' (10 items, $\alpha=.718$ ). Public self-consciousness was measured using seven items, such as 'I'm concerned about my style of doing things' (7 items, $\alpha=.807)$. Finally, social anxiety was measured using six items such as 'I get embarrassed very easily' ( 6 items, $\alpha=.846$ ).

\section{Analyses}

To address aim one, the answers to the open question about pre-loading were subjected to content analysis to count the frequency of times that different reasons were provided. T-tests were used to compare the main study measures between those who gave predominantly financial reasons and those who gave predominantly mood related reasons for pre-loading.

To address aim two, regression analyses were performed. Descriptive statistics and correlations were first conducted to check that assumptions for regression were met. Missing data were dealt with using pairwise deletion. Hierarchical linear regression was used to test 
whether T1 pre-loading, public/private self-consciousness and social anxiety would predict AUDIT and alcohol harms at T2 when controlling for these measures at T1.

To address aim three, the proposed mediation model was tested using the PROCESS macro in SPSS (Hayes, 2012). PROCESS is an add-on tool for SPSS, which uses the bootstrapping method to test estimated indirect effects. Mediation model four was used with T1 pre-loading as the predictor, $\mathrm{T} 1$ scores on the self-consciousness scale as mediators, and T2 harms as the outcome. The confidence intervals for the indirect effects were bias corrected and accelerated (BCa) based on 1000 samples.

\section{RESULTS}

\section{Sample}

In total, 416 students completed T1 and 325 students aged 18-30 (70.8\% female; $M$ age $=21.08$, $S D=3.01)$ completed $\mathrm{T} 1$ and $\mathrm{T} 2(78.1 \%$ drop out rate). Of the final sample of 325 , there were students from 22 different universities, but the majority (91\%) were from one institution that the study adverts targeted. Students at other institutions may have been recruited via their friends and contacts at the main study university. There were no differences between the majority of students who attended the main institution and the other participants. There were also no significant differences between those who completed T1 and T2 and those who failed to complete $\mathrm{T} 2$ on any of the outcome measures (as explored by independent samples t-tests).

\section{Open questions}

A total of 217 respondents wrote an answer to the question 'Why do you drink alcohol at home before going out?' An initial coding scheme comprising six categories was derived from the answers. The codes were derived deductively, by searching for specific reasons for engaging in pre-loading. Author 1 completed the initial coding and proposed the coding scheme. Author 2 independently checked a sub-sample $(\mathrm{N}=20)$ of the codes and agreed with their application. At this stage some participants had more than one code applied to their answer where they 
mentioned more than one of the following reasons. The codes were 'social/enjoyable $(\mathrm{N}=53)$, enhance positive mood $(\mathrm{N}=29)$, avoid negative mood/ gain confidence $(\mathrm{N}=24)$, financial reasons $(\mathrm{N}=162)$, to be in the mood to dance $(\mathrm{N}=10)$, and to get drunk $(\mathrm{N}=17)$. Example responses are contained in Table 1.

\section{[Insert Table 1]}

Due to the small number of responses for some codes, it was decided that all participants would be allocated to two groups: mood or financial reasons, depending on the first or predominant topic mentioned by the participant. Where a participant mentioned two or more reasons, the main code was derived by looking at what appeared to be the most important reason mentioned by that person, either as they mentioned it first or talked about it in a number of sentences. One hundred and ninety six respondents fell into one of these two categories, 110 of them reporting financial motives as the reason for pre-loading, and 86 reporting mood as the reason for preloading.

As expected, answers relating to financial reasons expressed the high cost of drinks in clubs compared to those available in the shops. However, those with mainly financial motives also referred to the need to drink to enjoy themselves and to gain confidence, for example:

So I have a good time when I'm out without spending ridiculous amounts of money in alcohol in the clubs (P419)

Because drinks in clubs are expensive and it makes the night cheaper, and to give me more confidence about dancing and socialising (P277)

So I don't spend as much money in the club on drinks because I'm already drunk enough (P149) 
Because of our focus on social anxiety and public and private self-consciousness, we explored the responses coded as 'mood related' in detail. Confidence was an important motive for preloading identified in the mood related responses. Comments suggested that drunkenness was required in order to go to nightclubs and dance, for example;

To gain confidence and fit in (P97)

To feel confident to dance and have a good time, I wish I didn't need it to have a good night out (P547)

I enjoy going out and am in the right mood for it if I'm already slightly tipsy, I would feel uncomfortable in a night club if I was sober (P521)

Other important facets related to mood were about socialising and enjoying time with friends. There were no significant differences (once an adjusted alpha level of .008 was applied to account for multiple t-tests) between respondents who reported mainly pre-loading for mood or financial reasons on any of the self-consciousness scales, T2 AUDIT, or T2 harms. However, respondents who reported pre-loading predominantly for financial reasons scored significantly higher on pre-loading at T2 $(M=3.87, S D=1.27)$ than those who engaged in it for mood reasons $(M=3.27, S D=1.52 ; \mathrm{t}(165.07)=2.93, \mathrm{p}=.004)$.

\section{Quantitative data}

\section{Descriptive statistics}

Means and standard deviations for all measures for the whole sample are shown in Table 2. The correlations showed that none of the predictor variables were strongly correlated with each other $(\mathrm{r}<.7)$, which is in accordance with the assumptions for regression. More specifically, all three components of the self-consciousness scale were weakly or moderately correlated with each other.

[Insert Table 2] 
Hierarchical regression analyses were performed to test if pre-loading and the three selfconsciousness subscales predicted T2 AUDIT and alcohol harms at T2. T1 AUDIT and T1 harms were entered first to control for past behaviour, followed by pre-loading, private and public selfconsciousness and social anxiety (Table 3).

\section{[Insert Table 3]}

\section{Predicting AUDIT}

T1 AUDIT predicted $77.6 \%$ of the variance in T2 AUDIT $\left(R^{2}=.776, F(1,318=1101.59, \mathrm{p}<001)\right.$. T1 Pre-loading added a small but significant amount of variance to the model $\left(\Delta R^{2}=.004\right.$; $p=.022$ ). Adding private and public self-consciousness and social anxiety did not result in a significant change to the variance explained by the model $\left(\Delta R^{2}=.004 ; p=.101\right)$.

\section{Predicting drinking harms}

$\mathrm{T} 1$ harms predicted $40.9 \%$ of the variance in T2 harms $\left(R^{2}=.409, F(1,323)=223.82, \mathrm{p}<001\right)$. $\mathrm{T} 1$ pre-loading added a small but significant amount of variance to the model $\left(\Delta R^{2}=.012\right.$; $p=.009)$. Adding private and public self-consciousness and social anxiety to the model resulted in a small but significant increase to the variance explained by the model $\left(\Delta R^{2}=.017 ; p=.025\right)$. Public self-consciousness and social anxiety both contributed significantly to the model (public self-consciousness, $\beta=.117, t=2.10, p=.037$; social anxiety, $\beta=-.144, t=2.89, p=.004$; Table 3 ). Higher scores on public self-consciousness, were associated with greater harms, whilst higher social anxiety were associated with fewer harms.

\section{Mediation analyses}

To explore the main aims of the study, mediation analyses were conducted to determine if public self-consciousness and social anxiety were mediators of the relationship between T1 preloading and T2 harms. Because it did not contribute to the regression models, private self- 
consciousness was not explored in the mediation analyses. Social anxiety was not a significant mediator between pre-loading and harms.

T1 Pre-loading was significantly associated with public self-consciousness (path a; $b=.933$, $p<.001)$. More pre-loading was associated with higher levels of public self-consciousness. Public self-consciousness was not significantly associated with harms (path $\mathrm{b} ; b=.037, p=.051$ ) but this was approaching significance and higher public self-consciousness was associated with greater harms. The total effect (c path) of pre-loading on harms was also significant ( $b=.565$, $p<.001$ ). Higher pre-loading was associated with greater harms. The direct effect ( $c^{\prime}$ path) of pre-loading was reduced by including public self-consciousness as a mediator $(b=.530, p<.001)$ but remained significant. There was a significant indirect effect of pre-loading on harms through public self-consciousness $(b=.034, \mathrm{BCa} \mathrm{CI}[0.003,0.084])$ with a small effect size $(b=$ .021 , BCa CI $[0.002,0.051])$. This result indicates that public self-consciousness is a significant partial mediator of the relationship between pre-loading and harms (Figure 1).

The mediation analysis was repeated for high risk and low risk drinkers (AUDIT 8+) in the sample. There was no mediation effect found in the low risk drinkers $(\mathrm{N}=122)$. However for high risk drinkers $(N=203)$ there was a significant mediation effect. Pre-loading at T1 was significantly associated with public self-consciousness (path a; $b=.985 p=.014$ ). More preloading was associated with higher levels of public self-consciousness. Public selfconsciousness was significantly associated with harms (path $\mathrm{b} ; b=.053, p=.042$ ) where higher public self-consciousness was associated with greater harms. The total effect (c path) of preloading on harms was also significant $(b=.451, p=.002)$. Higher pre-loading was associated with greater harms. The direct effect (c' path) of pre-loading was reduced by including public selfconsciousness as a mediator $(b=.400, p=.007)$, but remained significant. There was a significant indirect effect of pre-loading on harms through public self-consciousness $(b=.052, \mathrm{BCa} \mathrm{CI}$ $[0.005,0.142])$ with a small effect size $(b=.024$, BCa CI $[0.002,0.066])$. This result indicates that 
public self-consciousness is a significant partial mediator of the relationship between preloading and harms (Figure 2).

[Insert figures 1\&2]

\section{DISCUSSION}

This study first aimed to explore reasons for pre-loading in UK students, and whether different reasons were associated with increased drinking and harms. The second aim was to explore whether social anxiety, public and private self-consciousness and preloading differentially predict alcohol consumption and harms. Thirdly, it aimed to explore whether social anxiety, public and private self-consciousness mediated the relationship between pre-loading and alcohol consumption and harms.

In line with previous research, a range of reasons for pre-loading were identified, mostly related to either financial motives or a desire to change mood state. However even where financial reasons were noted as the main driver for pre-loading, the responses suggested that respondents needed to reach a certain level of intoxication to enhance their mood to improve the night out. These findings are in line with previous studies (Atkinson \& Sumnall, 2017; Barton \& Kerryn, 2014; Østergaard \& Andrade, 2014; Wells et al., 2009) in suggesting financial and mood related motivations for pre-loading. There were no differences between those who pre-loaded for financial or mood related reasons in our sample on the social anxiety, public and private self-consciousness measures. However, it is important to note that where financial reasons were discussed, the desire to save money may be due to a need to reach a desired level of intoxication to allow the individual to feel sufficiently equipped to deal with the social situation. Indeed, it appeared from our data that many respondents needed to be drunk to engage in the social activities they described, either to feel more confident, or to feel able to enjoy certain venues (for example where they did not feel the music or atmosphere was good). This matter requires further qualitative examination, to uncover which aspects of the night out are unenjoyable if one is not intoxicated. 
Pre-loading explained additional variance in hazardous alcohol consumption at T2 over and above hazardous alcohol consumption at T1. Pre-loading also explained additional variance in T2 harms over and above T1 harms. This suggests pre-loading is associated not only with increased consumption but also with increased negative impacts from drinking. This is in line with previous research (Foster \& Ferguson, 2014; Labhart, Wells, Graham, \& Kuntsche, 2014), which our results support in a UK student population. Understanding the factors that lead to increased consumption in this group is important in order to reduce both short- and long-term harms. Pre-loading was associated with increased reporting of alcohol-related harms in this sample, which is in agreement with study findings from international and non-student populations (Hughes et al., 2008; Miller et al., 2016). This relationship is a further cause for concern and a potential avenue for interventions aimed at students.

Together, social anxiety, public and private self-consciousness were not able to predict additional variance in hazardous alcohol consumption at T2 over and above hazardous alcohol consumption at T1 and T1 pre-loading. Social anxiety added to the prediction of T2 harms over and above T1 harms and T1 pre-loading. Higher levels of social anxiety were related to lower levels of harms experienced at T2. This might reflect that socially anxious individuals drank less, or it might reflect that they were less likely to report any harms due to feelings of concern. Previous research seems to support this negative relationship, suggesting that social anxiety is related to reduced risk for alcohol use and related problems, because highly socially anxious individuals are less likely to engage in social pre-loading (Keough et al., 2016). Because the relationships between social anxiety and the other study measures were weak, we are unable to speculate further as to the nature of this effect. Private self-consciousness did not add to the prediction of harms. However public self-consciousness added to the prediction of T2 harms over and above T1 harms and T1 pre-loading. Higher levels of public self-consciousness were associated with a greater number of harms at $\mathrm{T} 2$. 
Social anxiety was not a significant mediator, and private self-consciousness was not explored due to the previous non-significant findings. However, public self-consciousness mediated the relationship between pre-loading and harms. On closer examination of the data this effect was only observed in higher risk drinkers when compared to lower risk drinkers. However, the lack of effect in low risk drinkers could be due to low power. Those with higher levels of public selfconsciousness may be more vulnerable from the effects of pre-loading, experiencing more alcohol-related harms. Such individuals may be drinking more prior to going out in order to cope with the social demands of the situation. Previous research has suggested that social desirability may play a role in this relationship. Students who score highly in public selfconsciousness might model the behaviours of others when in a drinking context (LaBrie et al., 2008b), and they may need to drink more before engaging in a night out in order to relax and have fun. Research has also suggested that students who score highly in public selfconsciousness may not actively seek out heavy drinking contexts, but when they do they may drink more to cope (LaBrie et al., 2008a).

\section{Implications}

The link between public self-consciousness, pre-loading and harms suggests that individuals who score highly in public self-consciousness may need to be specifically targeted in interventions. The desire to reduce feelings of self-consciousness may be leading some students to become more intoxicated at pre-drinking events and thus more vulnerable to negative outcomes. Further insight on how to target this factor within interventions could be achieved by some further exploration of the experiences of public self-consciousness via qualitative work, which could feed into the development of intervention content. For example, self-consciousness has been related to embarrassment (Crawford \& Novak, 2013) and social embarrassment has been identified as a potential motivator for some groups of drinkers to reduce their drinking (Davies, Conroy, Winstock, \& Ferris, 2017). Thus measures that help individuals to feel less 
embarrassed (such as relaxation techniques) could be one strategy to encourage students who score highly in public self-consciousness to reduce their engagement in pre-loading.

A further useful way to target public self-consciousness might be a broader focus on helping publically self-conscious students to find alternative coping strategies other than drinking, when in social situations. Such interventions should be ideally be implemented before young people attend university, to provide them with healthier approaches to dealing with feeling selfconscious before social pressure to drink becomes prevalent. Cognitive Behaviour Therapy (CBT), for example, is often used to treat young people (Sauter, Heyne, \& Michiel Westenberg, 2009) and adults with anxiety disorders (Hofmann \& Smits, 2008), and has also be shown to reduce self-consciousness (Lundh \& Öst, 2001). Interventions that target specific traits, such as anxiety sensitivity for example, have also shown promise in reducing alcohol consumption (Conrod et al., 2013) in adolescents. These types of interventions educate participants about how their own personality traits are linked to substance use (Conrod, Castellanos, \& Mackie, 2008). Thus, a focus on understanding how being self-conscious links to drinking behaviours and outcomes might be useful for students.

\section{Limitations}

The study findings must be considered alongside its limitations. While some interesting relationships between the study measures were identified, the effects were relatively small. Furthermore, the use of self-report measures can be a particular issue considering surveys on alcohol use, which can be influenced by social desirability and potentially inaccurate recall. Nearly all participants attended one university, which makes generalizing difficult. Additionally, it is possible that four weeks is not enough time to examine the effects of certain factors on drinking behaviour. Following the example of LaBrie et al (2016), a longer follow-up of six months and a year would have given us a more complete picture of the factors associated with pre-loading. Furthermore, the scale that we used in this study to measure selfconsciousness is a relatively old measure, and a revised version was proposed by Schier and 
Carver (1985). However, the revision was mainly aimed to make the scale relevant to the general population, rather than university students. Given that university students was our target population, we considered the scale of Fenigstein et al (1975) appropriate as it has been applied in student populations in recent studies (Crawford \& Novak, 2013). Interestingly, Martin and Debus (1999) suggested an alternative structure for the revised scale, one that divides the private self-consciousness subscale into rumination and 'monitoring aspects of self'. A further study could use this revised scale to understand if student pre-loading is related to these subscales.

It should also be noted that pre-loading is not a unitary phenomenon. Keough et al (2016) made an important distinction between solitary and social pre-loading and found a positive relationship between social anxiety and solitary pre-loading. Additionally, there was a positive relationship between solitary pre-loading and alcohol-related problems, although not with alcohol use. On the other hand, there was a negative relationship between social anxiety and social pre-loading, and this was associated with lower levels of alcohol consumption and harms (Keough et al., 2016). These results illustrate the importance of distinguishing between different types of pre-loading. We did not specifically distinguish between drinking in a group or alone in our measures, and so this is an area for further exploration. Furthermore, our pre-loading measure was focussed on 'home' drinking prior to going out, and this may not capture other aspects of pre-loading such as in a restaurant prior to going to a bar or club (which has also been referred to as 'side loading' (Forsyth, 2010)). Our measure may fail to capture those students drinking at friends' residences, which may be interpreted as outside of the home. However, in a pilot of the measures, 'at home' drinking was thought of as being anyone's home, although the pilot itself was small $(N=10)$. This could have important implications, for example those who are high in social anxiety and public self-consciousness might be less likely to attend pre-drinking events at others houses than to drink at their own residences prior to a night out. Conclusions 
Our findings concur with previous studies that financial motives for pre-loading are prevalent, but improving mood and gaining confidence to engage in social situations are also important. Pre-loading was associated with hazardous alcohol consumption and drinking harms. Students who scored highly in public self-consciousness appeared to be at greater risk of harms from preloading. Interventions could incorporate measures to reduce public self-consciousness, in order to reduce alcohol consumption and harms. 


\section{REFERENCES}

Atkinson, \& Sumnall. (2017). 'Isn't it mostly girls that do pre-drinks really?' Young men and women's accounts of pre-loading in the UK. Drugs: Education, Prevention and Policy, 110. doi: 10.1080/09687637.2017.1377154

Babor, Caetano, Casswell, Edwards, Giesbrecht, Graham, ... Room. (2010). Alcohol No Ordinary Commodity - research and public policy. Oxford, UK: Oxford University Press.

Babor, Higgins-Biddle, Saunders, \& Monteiro. (2001). The Alcohol Use Disorders Identification Test, Guidelines for Use in Primary Care (2nd edition ed.). Geneva: World Health Organization.

Barton, \& Kerryn. (2014). "I don't really like the pub [...]": reflections on young people and preloading alcohol. Drugs and Alcohol Today, 14(2), 58-66. doi: 10.1108/DAT-12-20130055

Conrod, Castellanos, \& Mackie. (2008). Personality-targeted interventions delay the growth of adolescent drinking and binge drinking. Journal of Child Psychology and Psychiatry, 49(2), 181-190. doi: 10.1111/j-1469-7610.2007.01826.x

Conrod, O'Leary-Barrett, Newton, Topper, Castellanos-Ryan, Mackie, \& Girard. (2013). Effectiveness of a Selective, Personality-Targeted Prevention Program for Adolescent Alcohol Use and Misuse A Cluster Randomized Controlled Trial. Jama Psychiatry, 70(3), 334-342. doi: 10.1001/jamapsychiatry.2013.651

Crawford, \& Novak. (2007). Resisting Peer Pressure: Characteristics Associated With Other-Self Discrepancies in College Students' Level of Alcohol Consumption. Journal of Alcohol and Drug Education 51(1), 35-62.

Crawford, \& Novak. (2013). The Effects of Public Self-Consciousness and Embarrassability on College Student Drinking: Evidence in Support of a Protective Self-Presentational Model. Journal of Social Psychology, 153(1), 109-122. doi: 10.1080/00224545.2012.711381

Davies, Conroy, Winstock, \& Ferris. (2017). Motivations for reducing alcohol consumption: An international survey exploring experiences that may lead to a change in drinking habits. Addictive Behaviors, 75, 40-46. doi: http://dx.doi.org/10.1016/j.addbeh.2017.06.019

Davies, \& Joshi. (2018). "Here's to a Night of Drunken Mistakes": Exploring Experiences, Regrets, and Optimism in Young Adult Drinkers. Substance Use \& Misuse, 1-10. doi: 10.1080/10826084.2018.1461227

Davies, Martin, \& Foxcroft. (2016). Age differences in alcohol prototype perceptions and willingness to drink in UK adolescents. Psychology, Health \& Medicine, 21(3), 317-329. doi: 10.1080/13548506.2015.1051556

Davoren, Demant, Shiely, \& Perry. (2016). Alcohol consumption among university students in Ireland and the United Kingdom from 2002 to 2014: a systematic review. Bmc Public Health, 16(1), 1-13. doi: 10.1186/s12889-016-2843-1

Fenigstein, Scheier, \& Buss. (1975). PUBLIC AND PRIVATE SELF-CONSCIOUSNESS ASSESSMENT AND THEORY. Journal of Consulting and Clinical Psychology, 43(4), 522527. doi: $10.1037 / \mathrm{h} 0076760$

Forsyth. (2010). Front, side, and back-loading: Patrons' rationales for consuming alcohol purchased off-premises before, during, or after attending nightclubs. Journal of Substance Use, 15(1), 31-41. doi: 10.3109/14659890902966463

Foster, \& Ferguson. (2014). Alcohol 'Pre-loading': A Review of the Literature. Alcohol and Alcoholism, 49(2), 213-226. doi: 10.1093/alcalc/agt135

Foster, \& Neighbors. (2013). Self-consciousness as a moderator of the effect of social drinking motives on alcohol use. Addictive Behaviors, 38(4), 1996-2002. doi: 10.1016/j.addbeh.2013.01.011

Ham, Bacon, Carrigan, Zamboanga, \& Casner. (2016). Social anxiety and alcohol use: The role of alcohol expectancies about social outcomes. Addiction Research \& Theory, 24(1), 9-16. doi: 10.3109/16066359.2015.1036242 
Hayes. (2012). PROCESS: A versatile computational tool for observed variable mediation, moderation, and conditional process modeling. Retrieved 19 January 2018, from http://www.afhayes.com/ public/process2012.pdf

Hofmann, \& Smits. (2008). COGNITIVE-BEHAVIORAL THERAPY FOR ADULT ANXIETY DISORDERS: A META-ANALYSIS OF RANDOMIZED PLACEBO-CONTROLLED TRIALS. The Journal of clinical psychiatry, 69(4), 621-632.

Hughes, Anderson, Morleo, \& Bellis. (2008). Alcohol, nightlife and violence: the relative contributions of drinking before and during nights out to negative health and criminal justice outcomes. Addiction, 103(1), 60-65. doi: 10.1111/j.1360-0443.2007.02030.x

Keough, Battista, O'Connor, Sherry, \& Stewart. (2016). Getting the party started--Alone: Solitary predrinking mediates the effect of social anxiety on alcohol-related problems. Addict Behav, 55, 19-24. doi: 10.1016/j.addbeh.2015.12.013

Kypri, Cronin, \& Wright. (2005). Do university students drink more hazardously than their nonstudent peers? Addiction, 100(5), 713-714. doi: 10.1111/j.1360-0443.2005.01116.x

Labhart, Ferris, Winstock, \& Kuntsche. (2017). The country-level effects of drinking, heavy drinking and drink prices on pre-drinking: An international comparison of 25 countries. Drug and Alcohol Review, n/a-n/a. doi: 10.1111/dar.12525

Labhart, Wells, Graham, \& Kuntsche. (2014). Do Individual and Situational Factors Explain the Link Between Predrinking and Heavier Alcohol Consumption? An Event-Level Study of Types of Beverage Consumed and Social Context. Alcohol and Alcoholism, 49(3), 327335. doi: 10.1093/alcalc/agu001

LaBrie, Earle, Hummer, \& Boyle. (2016). Is Prepartying a Cause of Heavy Drinking and Consequences Rather than just a Correlate? A Longitudinal Look at the Relationship Between Prepartying, Alcohol Approval, and Subsequent Drinking and Consequences. Substance use \& misuse, 51(8), 1013-1023. doi: 10.3109/10826084.2016.1152493

LaBrie, Hummer, \& Neighbors. (2008a). Self-consciousness moderates the relationship between perceived norms and drinking in college students. Addictive Behaviors, 33(12), 15291539. doi: 10.1016/j.addbeh.2008.07.008

LaBrie, Pedersen, Neighbors, \& Hummer. (2008b). The role of self-consciousness in the experience of alcohol-related consequences among college students. Addictive Behaviors, 33(6), 812-820. doi: 10.1016/j.addbeh.2008.01.002

LaBrie, Pedersen, Neighbors, \& Hummer. (2008c). The role of self-consciousness in the experience of alcohol-related consequences among college students. Addictive Behaviors, 33(6), 812-820. doi: 10.1016/j.addbeh.2008.01.002

Lundh, \& Öst. (2001). Attentional Bias, Self-consciousness and Perfectionism in Social Phobia Before and After Cognitive-Behaviour Therapy. Scandinavian Journal of Behaviour Therapy, 30(1), 4-16. doi: 10.1080/02845710117841

Martin, \& Debus. (1999). Alternative Factor Structure for the Revised Self-Consciousness Scale. Journal of Personality Assessment, 72(2), 266-281. doi: 10.1207/S15327752JP720211

McCreanor, Lyons, Moewaka Barnes, Hutton, Goodwin, \& Griffin. (2016). 'Drink a 12 box before you go': pre-loading among young people in Aotearoa New Zealand. Kōtuitui: New Zealand Journal of Social Sciences Online, 11(1), 36-46. doi: 10.1080/1177083X.2015.1037314

Miller, Droste, De Groot, Palmer, Tindall, Busija, ... Wiggers. (2016). Correlates and motives of pre-drinking with intoxication and harm around licensed venues in two cities. Drug and Alcohol Review, 35(2), 177-186. doi: 10.1111/dar.12274

Østergaard, \& Andrade. (2014). Who pre-drinks before a night out and why? Socioeconomic status and motives behind young people's pre-drinking in the United Kingdom. Journal of Substance Use, 19(3), 229-238. doi: 10.3109/14659891.2013.784368

Park, Sher, \& Krull. (2006). Individual differences in the "Greek effect" on risky drinking: The role of self-consciousness. Psychology of Addictive Behaviors, 20(1), 85-90. doi: 10.1037/0893-164x.20.1.85 
Rehm, Room, van den Brink, \& Jacobi. (2005). Alcohol use disorders in EU countries and Norway: An overview of the epidemiology. European Neuropsychopharmacology, 15(4), 377-388. doi: 10.1016/j.euroneuro.2005.04.005

Sauter, Heyne, \& Michiel Westenberg. (2009). Cognitive Behavior Therapy for Anxious Adolescents: Developmental Influences on Treatment Design and Delivery. Clinical Child and Family Psychology Review, 12(4), 310-335. doi: 10.1007/s10567-009-0058-z

Scheier, \& Carver. (1985). The Self-Consciousness Scale: A Revised Version for Use with General Populations1. Journal of Applied Social Psychology, 15(8), 687-699. doi: 10.1111/j.15591816.1985.tb02268.x

Schry, \& White. (2013). Understanding the relationship between social anxiety and alcohol use in college students: a meta-analysis. Addict Behav, 38(11), 2690-2706. doi: 10.1016/j.addbeh.2013.06.014

Wells, Graham, \& Purcell. (2009). Policy implications of the widespread practice of 'predrinking' or 'pre-gaming' before going to public drinking establishments-are current prevention strategies backfiring? Addiction, 104(1), 4-9. doi: 10.1111/j.13600443.2008.02393.x 


\section{TABLES AND FIGURES}

Table 1: Categories, number of responses coded in each, and examples from content analysis of opened ended responses to 'why do you drink alcohol at home before going out'

\begin{tabular}{lll}
\hline Code & N & Example \\
\hline Social reasons & 53 & I can get bored while out if I haven't had a bit to drink \\
& & already and it's a nice social way to get ready for the \\
& & evening (P243). \\
Enhance positive mood & 29 & A way of relaxing and getting in the mood as you're \\
& & getting ready (P460)
\end{tabular}

Avoid negative mood/gain

24 To feel confident to dance and have a good time, I wish

confidence

I didn't need it to have a good night out (P457)

Financial reasons

To be in the mood to dance

To get drunk
162 It's a cheaper way to get drunk before getting to the club, therefore you spend less money in the club (P136)

10 It sets me up for the nightclub, so I can immediately go in and enjoy myself, without having to pay lots of money to get to a level of drunkenness where I can dance, etc. (P108)

17 I enjoy the effects of being tipsy/mildly drunk. It is expensive to achieve this on a night out, so cheaper to "pre drink" at home, then go out (P156) 
Table2. Means, standard deviations and Pearson correlations between public/private self-consciousness, social anxiety at baseline and AUDIT, preloading and drinking harms at follow up

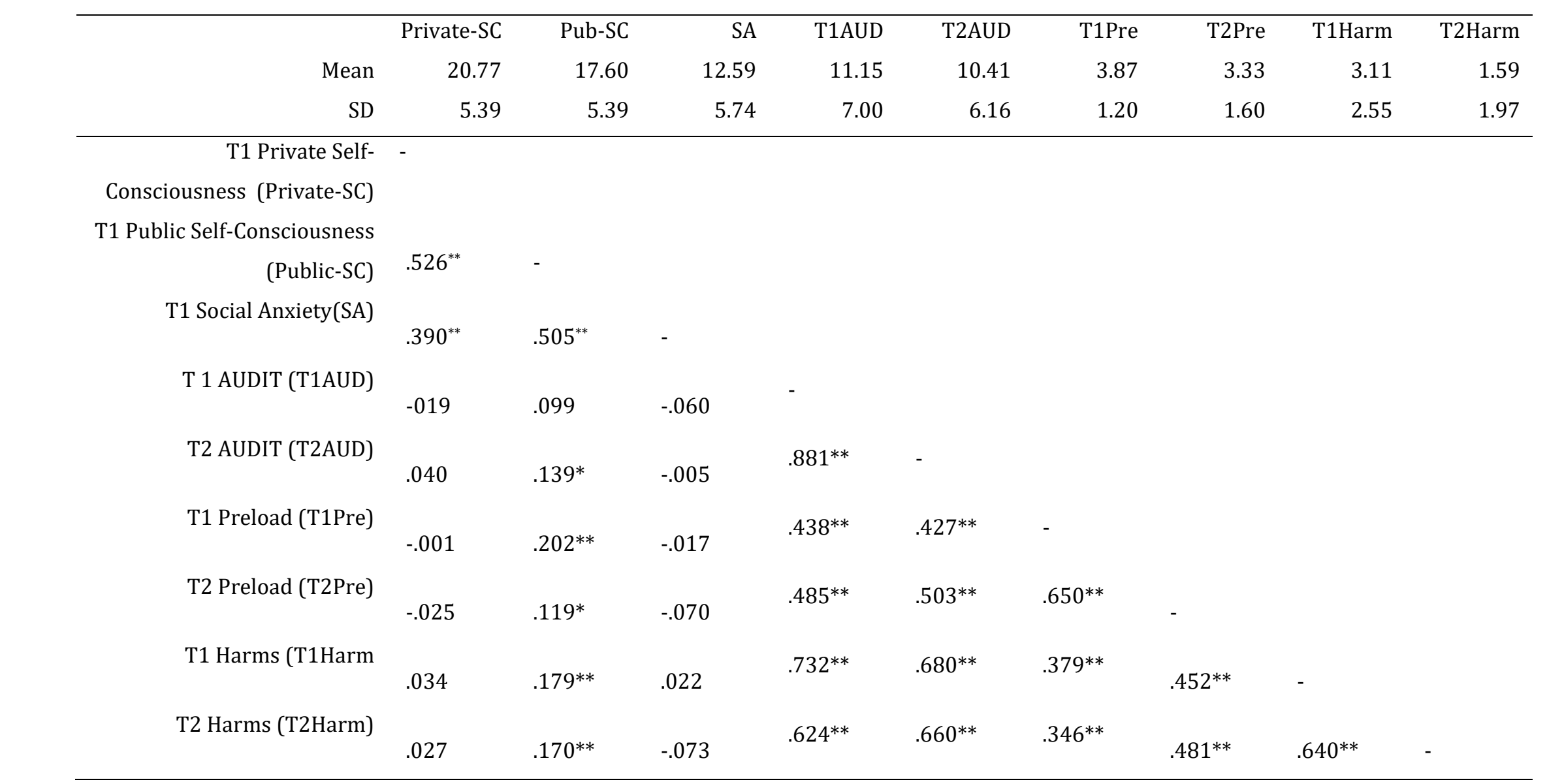

Note ${ }^{* *} p<.01 * p<.05$ 
Table 3 Results of hierarchical regression models predicting AUDIT and harms at T2 from T1 AUDIT and harms, T1 pre-loading, public/private selfconsciousness and social anxiety sub-scales

\begin{tabular}{|c|c|c|c|c|c|c|}
\hline \multirow[t]{2}{*}{ Variables } & \multicolumn{3}{|c|}{ Predicting T2 AUDIT } & \multicolumn{3}{|c|}{ Predicting T2 Harms } \\
\hline & $\beta$ & $t$ & $p$ & $\beta$ & $t$ & $p$ \\
\hline Step 1 Constant & & 1.236 & .217 & & .438 & .662 \\
\hline T1 AUDIT /Harms & .881 & 33.190 & .000 & .640 & 14.960 & .000 \\
\hline Step 2 Constant & & -1.065 & .287 & & -2.115 & .035 \\
\hline T1 AUDIT /Harms & .851 & 29.030 & .000 & .594 & 12.972 & .000 \\
\hline T1 Pre-loading & .068 & 2.304 & .022 & .120 & 2.627 & .009 \\
\hline Step 3 Constant & & -2.530 & .012 & & -1.294 & .197 \\
\hline T1 AUDIT /Harms & .853 & 29.154 & .000 & .585 & 12.804 & .000 \\
\hline T1 Pre-loading & .064 & 2.142 & .033 & .098 & 2.107 & .036 \\
\hline Private-SC & .039 & 1.237 & .217 & .002 & .044 & .965 \\
\hline Public-SC & .018 & .519 & .604 & .117 & 2.100 & .037 \\
\hline Social Anxiety & .025 & .787 & .432 & -.144 & -2.894 & .004 \\
\hline
\end{tabular}




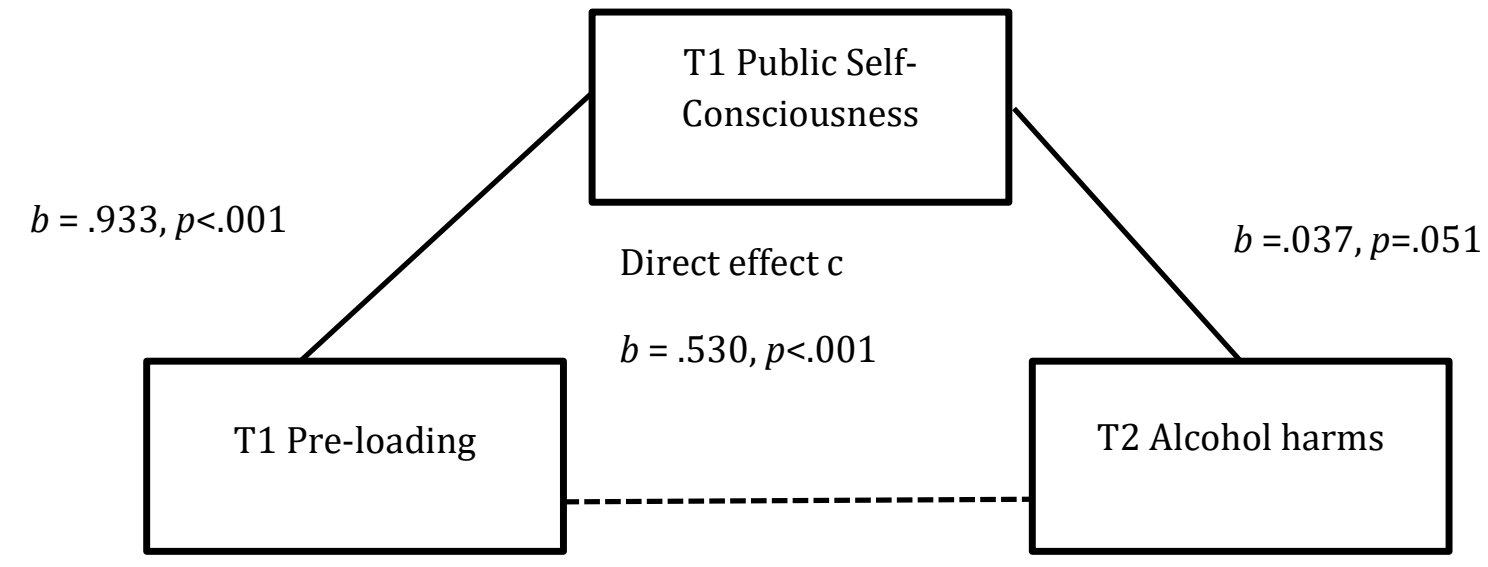

Indirect effect

$b=.034, \mathrm{p}<.001,95 \%$ CI $[0.003,0.084]$

Figure 1: Mediation model of T1 Pre-loading as a predictor of T2 Harms mediated by Public S-C for the whole sample. The confidence interval for the indirect effect is a BCa bootstrapped CI based on 1000 samples, $R^{2}=.120$ 


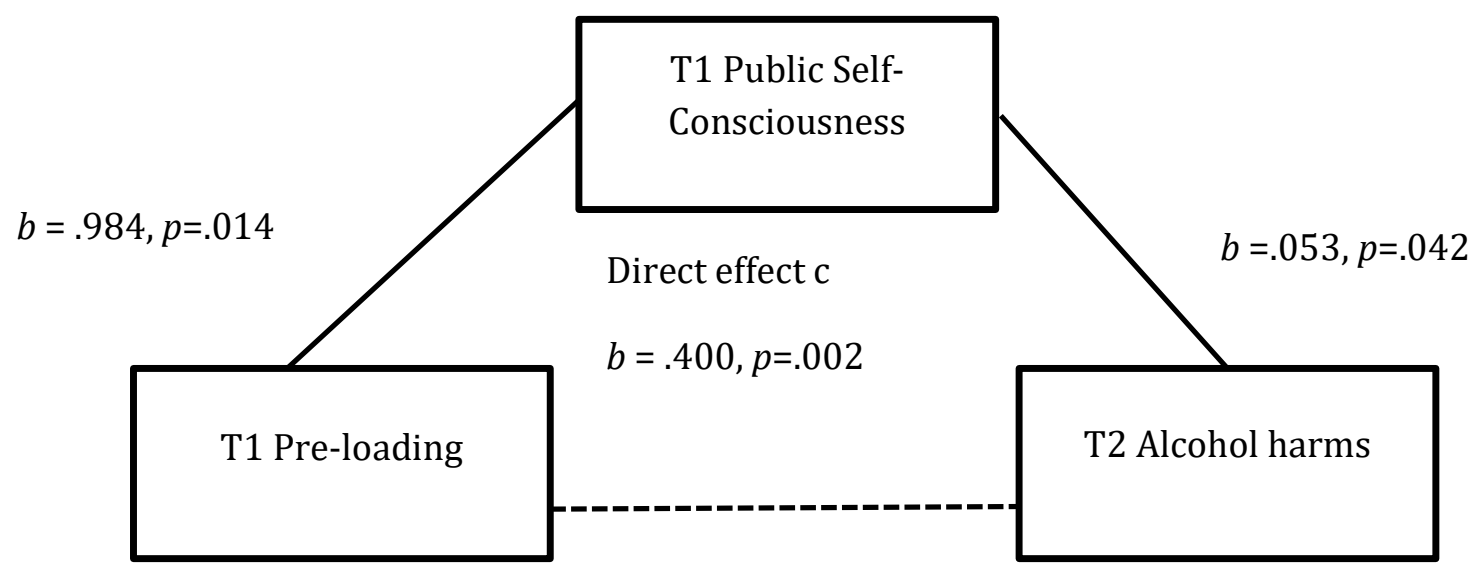

Indirect effect

$b=.052, \mathrm{p}<.001,95 \%$ CI $[0.005,0.142]$

Figure 2: Mediation model of T1 Pre-loading as a predictor of T2 Harms mediated by Public S-C for the high risk drinkers only. The confidence interval for the indirect effect is a BCa bootstrapped CI based on 1000 samples, $R^{2}=.045$ 
